\title{
Design and Research of Heat Recovery Shield at Hot Rolling Mill in Steel Industry
}

\author{
Devan P D, Arun K K
}

\begin{abstract}
This paper presents the heat transfer analysis of hot rolling bar (HRB), exactly between roughing mill and steckel mill. The bar is heated up to $1250^{\circ} \mathrm{C}$ in the furnace for three hours. The hot bar stock enters the roughing mill. Here, the bar stocks are fed for seven passes and the thickness is reduced to 25 $\mathrm{mm}$. The elongate hot bar then travels approximately $126 \mathrm{~m}$ in the open air surrounding over roller before entering the steckel mill. Transfer bar is rolled in steckel mill in 3 to 7 passes to achieve required thickness. It is adopted with the most sophisticated rolling technology of level-2 automation to achieve the target thickness, profile and flatness. There is a considerable loss of heat during this travel due to convection and radiation. This has been identified as the place, where the objective is to minimize heat loss taking place. Catia V5 is used for modeling and Ansys Workbench is used for thermal analysis.
\end{abstract}

Index Terms - Convection, Heat Transfer, Hot Rolling Bar, Radiation, Steckel mill

\section{INTRODUCTION}

Steel industry plays an important role in an economical growth of a country.Nation strongly believes the steel production will leads the country economy in to newer heights. Steel is a product of an iron. Iron is deduced from magnate and hematite ores. The reduction process involves and consumes larger heat energy. Electricity, coal and sometimes natural gas also used to generate heat.Production method, type of coal and ore used determines the efficiency of steel making process. Steel is made through three different processes such as blast furnace, arc furnace and induction furnace. After this process steel would be casted in the form of slab or billet.The slab thickness is reduced based on needs in Hot Roll Mill (HRM) by undergoing serious of rolling process.Hot roll mill consists of reheating furnace, edge roller, roughing mill, stecel mill, coiler and cooling zone. In re-heating furnace, the slab is heated up to $1200^{\circ} \mathrm{C}$ and the thickness is reduced to $50 \mathrm{~mm}$ in roughing mill. At finishing mill the slab size is reduced to 1-2 mm approximately.Roughing mill is a four-high reversible stand mill. The slabs are carried by means of roller table. This mill consists of two back up rolls and two work rolls. The slabs are passed through the work rolls. The maximum number of passes will be 7 . In this mill, the thickness of slabs is reduced to $25 \mathrm{~mm}$. Hot slabs are travelling for a long distance between roughing and steckel mill (126 m). Since the distance is more, there will be a considerable temperature drop in the slabs. The metallurgical properties of a finished steel product is purely depends on temperature of the slab during the hot rolling process. To get a steel with desired qualities, the temperature must be maintained throughout the hot rolling process.

Between roughing and steckel mill of HRM, where there is a considerable loss of heat due to convection and radiation when the bar moves from roughing to steckel mill. Due to loss of heat, power required to heat the slab increases and thus in turn production cost also increases. The objective is to minimize the fuel consumption and work requirement by recovering the wasted heat with the help of a metal shield, thus resulting in the increase in production rate and reduction in production cost.

Steckel mill, also known as a reversible finishing mill is like a reversing rolling mill except two coilers are used to feed the material through the mill. One coiler is on the entrance side and the other on the exit side. The coilers pull the material through the mill; therefore, the process is more like drawing than rolling. The material is fed back and forth through the mill until the desired thickness is reached.

Waste heat can be recovered from high temperature slag based on Time Temperature Transformation (TTT) curves. Through SHTT experiments TTT curves could be established. Through multi stage control method the waste heat can be recovered [1].

Temperature loss of partially-finished slabs between the mill stand is inevitable until it exposed to the atmosphere. Heat transfer by radiation can be reduced by introducing low emissivity shield material between two sides. Since the radiation is a major source of heat loss, shield makes resistance to radiation heat transfer. Shields are also can be fixed on path of the slab travels to reduce more heat loss [2].

The paper focuses exactly between Roughing and Steckel Mill of HRM, where there is a considerable loss of heat due to convection and radiation when the bar moves from Roughing to Steckel mill. Due to the loss of heat, power required to heat the slab increases and thus in turn production cost also increases.The main objective is to minimize the fuel consumption and work requirement by recovering the wasted heat with the help of a metal shield, thus resulting in the increase in production rate and reduction in production cost.
Revised Manuscript Received on August 19, 2019.

Devan P D, Department of Mechanical Engineering, Kumaraguru College of Technology, Coimbatore, Tamil Nadu, India. (E-mail: devan.pd.mec@kct.ac.in)

Arun K K, Department of Mechanical Engineering, Kumaraguru College of Technology, Coimbatore, Tamil Nadu, India. 


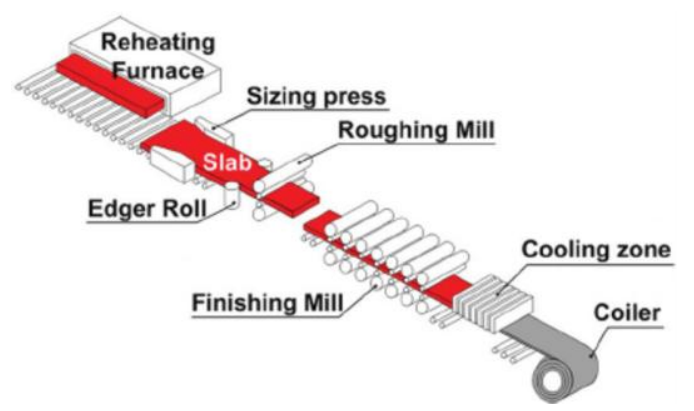

Fig.1. Schematic diagram of Hot Rolling Mill (HRM)

\section{SELECTION OF RADIATION SHIELD MATERIALS}

The design calculation is based on the transfer of heat taking place on the slab in between the roughing mill and steckel mill. For this purpose, both convection and radiation models were considered. With the help of calculations, the thickness, number and material of shield were selected. The range of materials chosen for the radiation shield based on low emissivity is Aluminium, Copper, Steel and Galvanised Steel. But aluminium cannot be machined easily into shields. Compared to copper, steel and galvanized steel are readily available in market. So, they are chosen as the materials for the recovery shield.

\section{TABLE 1SPECIFICATIONS OF HRM}

\begin{tabular}{ll}
\hline $\begin{array}{l}\text { Hot metal slab size } \\
\text { Distance between roughing and steckel } \\
\text { mill }\end{array}$ & $126 \mathrm{~m}$ \\
Velocity of the hot metal & $3.5 \mathrm{~m} / \mathrm{sec}$ \\
Weight of the material & $15,000 \mathrm{~kg}$ \\
Mean specific heat & $0.483 \mathrm{~kJ} / \mathrm{kg} \mathrm{K}$ \\
Temperature of the coming out of $1000^{\circ} \mathrm{C}$ \\
$\begin{array}{l}\text { Roughing mill } \\
\text { Ambient temperature }\end{array}$ \\
$\begin{array}{l} \\
\text { Heat available out of roughing Mill }\end{array}$ & $60^{\circ} \mathrm{C}$ \\
\hline
\end{tabular}

\section{CALCULATION OF HEAT LOSS}

\section{A. Without Thermal Shield}

Heat loss by radiation $\mathrm{q}=2 \varepsilon \sigma\left(\mathrm{T}_{\mathrm{h}}{ }^{4}-\mathrm{Tc}^{4}\right) \mathrm{A}=12716.86 \mathrm{~kW}$

Heat loss by convection $\mathrm{Q}=2 \mathrm{~h} \mathrm{~A}(\Delta \mathrm{T})=631.63 \mathrm{~kW}$

Total Heat Loss from hot metal Q=13348.49 kW

Temperature in the slab $\mathrm{T}_{\mathrm{h}}=933.25^{\circ} \mathrm{C}$ and $\mathrm{Tt}=901.74{ }^{\circ} \mathrm{C}$

B. With Thermal Shield (Steel)

Heat loss by radiation $\mathrm{q} / \mathrm{A}=\sigma\left(\mathrm{T}_{1}{ }^{4}-\mathrm{T}_{2}{ }^{4}\right) * 1 /(1 / \varepsilon 1+1 / \varepsilon 2-$

$$
\text { 1) }(\mathrm{q})=8637.38 \mathrm{~kW}
$$

Heat loss by convection $\mathrm{Q}=2 \mathrm{~h} \mathrm{~A}(\Delta \mathrm{T})=467.10 \mathrm{~kW}$

Total Heat Loss from hot metal Q $=9104.48 \mathrm{~kW}$

Temperature in the slab $\mathrm{T}_{\mathrm{h}}=954.47^{\circ} \mathrm{C}$ and $\mathrm{T}_{\mathrm{t}}=932.98^{\circ} \mathrm{C}$

\section{With Thermal Shield (Galvanized Steel)}

Heat loss by radiationq $=2 \varepsilon \sigma\left(\mathrm{T}_{\mathrm{h}}{ }^{4}-\mathrm{Tc}^{4}\right) \mathrm{A}=5084.73 \mathrm{~kW}$

Heat loss by convection $\mathrm{Q}=2 \mathrm{~h} \mathrm{~A}(\Delta \mathrm{T})=467.10 \mathrm{~kW}$

Total Heat Loss from hot metal $\mathrm{Q}=5552.29 \mathrm{~kJ} / \mathrm{sec}$

Temperature in the slab $\mathrm{T}_{\mathrm{h}}=972.23^{\circ} \mathrm{C}$ and $\mathrm{T}_{\mathrm{t}}=959.13{ }^{\circ} \mathrm{C}$
Thus, maximum temperature for slab is obtained in galvanized steel and thus galvanized steel is chosen as the material.

\section{SELECTION OF SHIELD THICKNESS}

The thickness of the shield is chosen as 5 and $10 \mathrm{~mm}$, as it is more than enough for the recovery shield. Their strengths are compared with the help of section modulus.

\section{TABLE 2SHIELD THICKNESS}

\begin{tabular}{ccc}
\hline Thickness & $5 \mathrm{~mm}$ & $10 \mathrm{~mm}$ \\
Moment of Inertia & $10.59 * 10^{8}$ & $13.64 * 10^{8}$ \\
Section Modulus & $19.37 * 10^{5}$ & $20.05 * 10^{5}$ \\
\hline
\end{tabular}

From the above table $5 \mathrm{~mm}$ is chosen, as the section modulus of it is closer to $10 \mathrm{~mm}$, so it, is enough for the purpose as the main concern is the material and number of shields regarding the heat radiation of the shield.

\section{SELECTION OF SHIELD THICKNESS}

Let the number of shields be $n$, length of shields be $t$, air gap between shields be $\mathrm{g}$. The total span is $126 \mathrm{~m}$.

Thus, $\mathrm{n} * \mathrm{t}+(\mathrm{n}-1) * \mathrm{~g}=126$

With the help of this formula, a table 3 and 4 is generated with the variables $n, t$ and $g$.

\section{TABLE 3SELECTION OF NUMBER OF SHIELDS}

\begin{tabular}{lll}
\hline No. of shields & Length $(\mathbf{m})$ & Air gap $(\mathbf{m})$ \\
\hline 12 & 10 & 0.545 \\
11 & 10 & 1.6 \\
10 & 10 & 2.88 \\
12 & 9 & 1.64 \\
11 & 9 & 2.7 \\
12 & 8 & 2.72 \\
\hline
\end{tabular}

The air gap in between the shields is assumed to have the heat losses like the condition without a radiation shield.

Maximum temperature is attained for the first case and thus the number of shields is chosen to be 12 , each with a span of $10 \mathrm{~m}$.

\section{MODELING OF RADIATION SHIELD}

The modeling of the heat radiation shield is done with the help of Catia V5. For this purpose, three models of radiation shields were considered. Each radiation shield varies in the surface area, fillets produced, etc. The models of the respective shields are as follows.

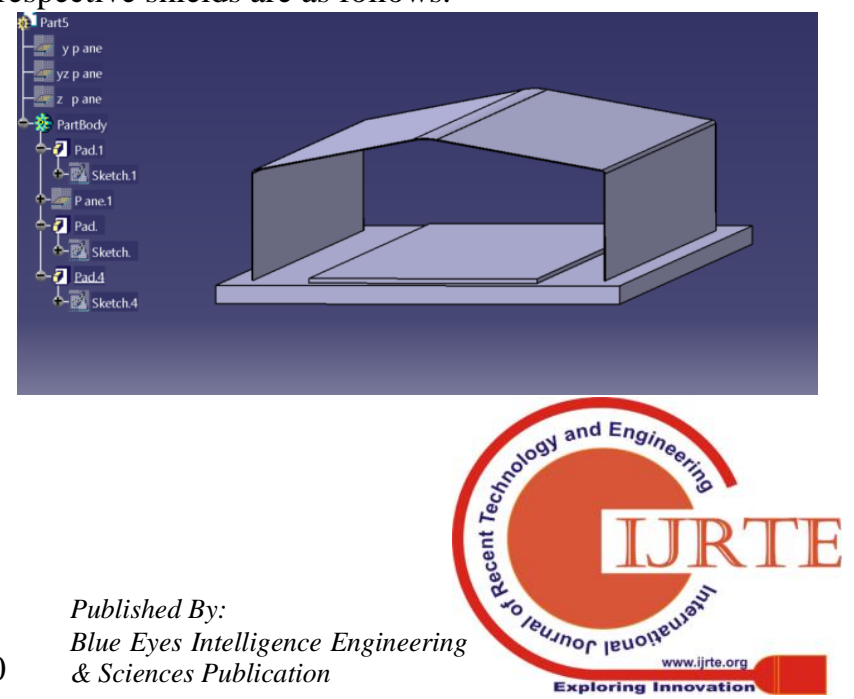




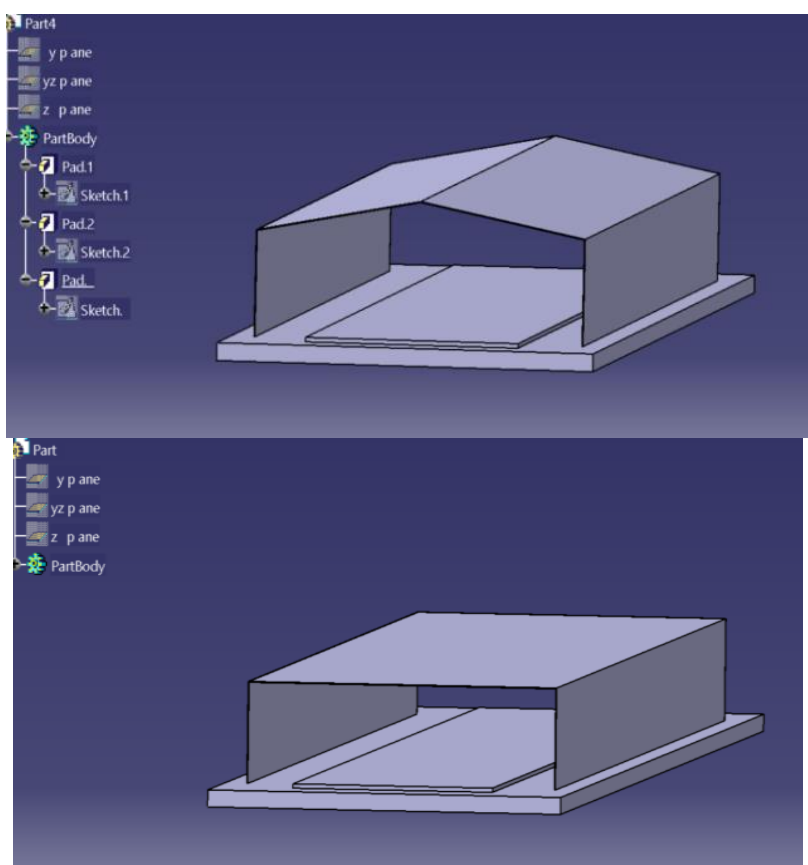

Fig.2. Modeling of radiation shields profile 1,2 and 3

\section{THERMAL ANALYSIS RESULTS}

Transient thermal analysis is performed to assess the effects of the heat dissipation in the heated slab. Since, the process takes place in a dynamic condition; it would be safe to take into consideration the "transient" nature of analysis. The analysis is mainly performed using Ansys Workbench 16.0. The boundary conditions are in accordance with the actual temperature of the slab and shield while moving in the roller table as well as the heat transfer co-efficient from the radiation and convection models that have been evaluated through manual calculation as seen in table. An initial time step of 2 minutes over 100 steps per minute is assumed to get accurate results. The boundary conditions applied to the transient thermal analysis are shown in table 4. The pictorial representation is seen in fig 3 .

\section{TABLE.4BOUNDARY CONDITIONS}

\begin{tabular}{ll}
\hline \multicolumn{1}{c}{ Analysis type } & \multicolumn{1}{c}{ Boundary conditions } \\
\hline Transient Thermal & $h=4 \mathrm{~W} / \mathrm{m}^{2} \mathrm{~K}$ \\
(Convection and & Heat flow in roller table $=0 \mathrm{~W}$ \\
Radiation model) & Temperature $=995^{\circ} \mathrm{C}$ \\
& Ambient Temperature $=30^{\circ} \mathrm{C}$ \\
\hline
\end{tabular}

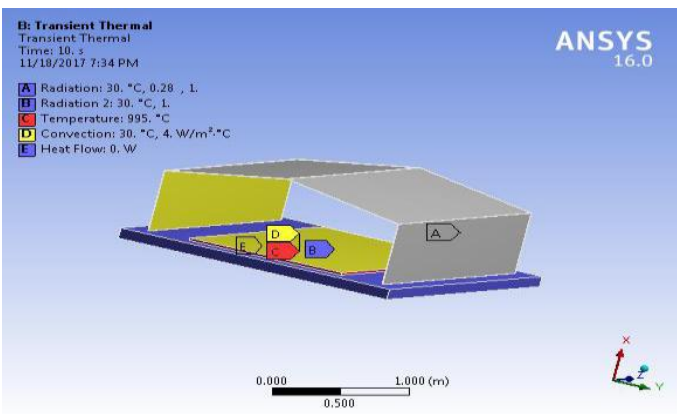

Fig.3. Boundary conditions for radiation shields

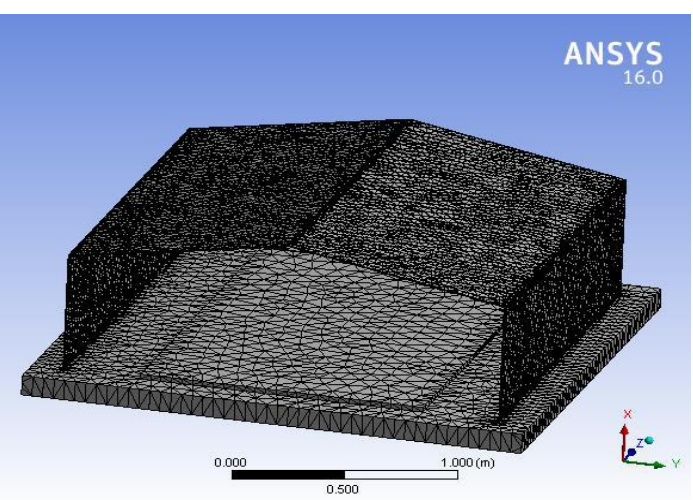

Fig.4. Mesh model of the radiation shields



Fig.5. Temperature distribution

The shield is subjected to analysis through the transient method wherein the thermal conditions and boundary conditions relating to time are applied in sequence, the analysis is mainly performed to infer the results mainly to check the temperature distribution and the heat flux.
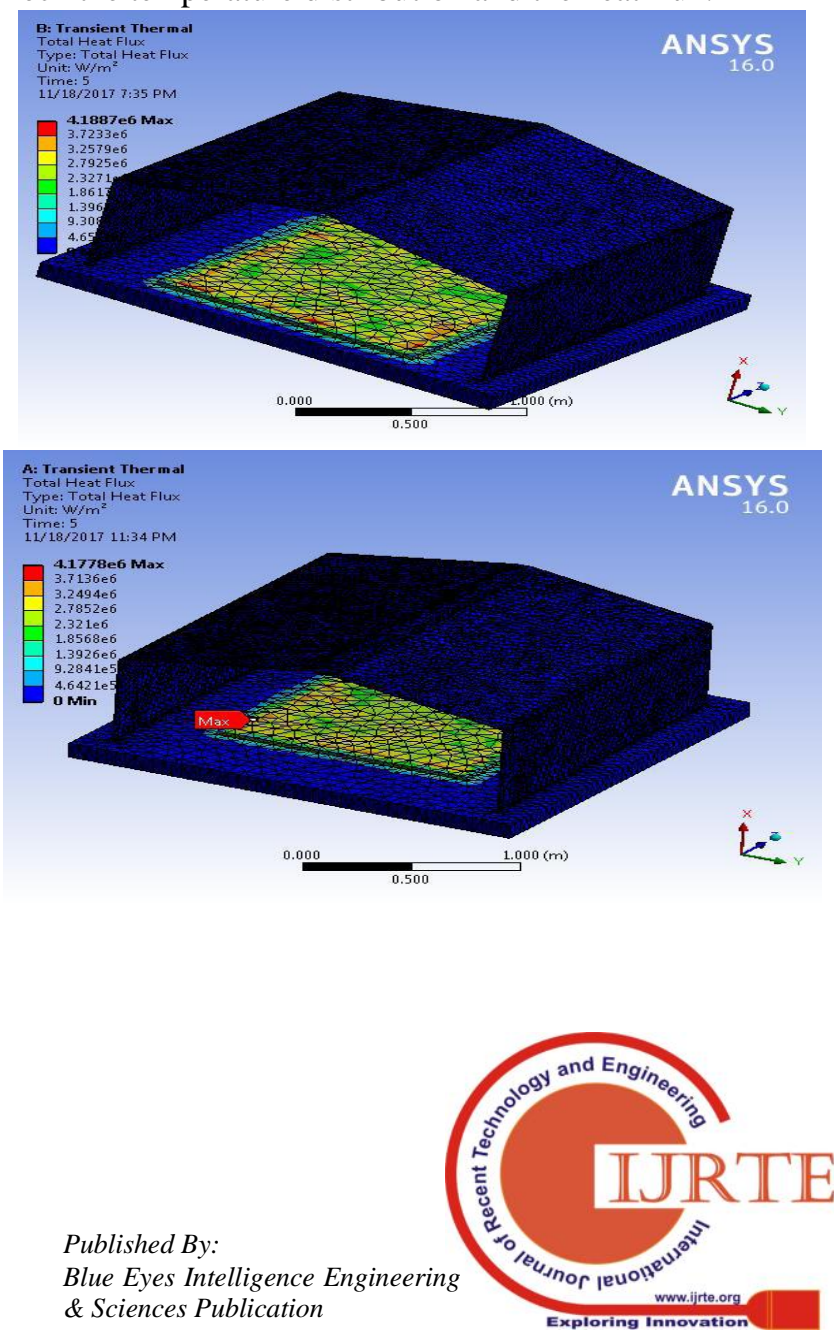


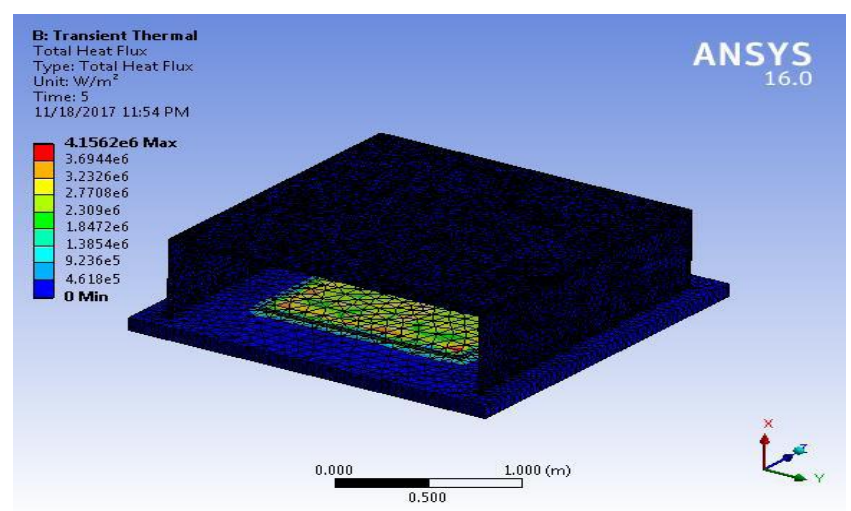

Fig.6. Heat flux in profile 1,2 and 3

It is observed that the heat flux produced is the highest in profile I.

\section{TABLE 5THERMAL ANALYSIS}

\begin{tabular}{ccc}
\hline Shield & $\begin{array}{c}\text { Maximum } \\
\text { temperature }\left({ }^{\circ} \mathbf{C}\right)\end{array}$ & Heat Flux $(\mathbf{W})$ \\
\hline Profile 1 & 995 & $4.1887 * 10^{6}$ \\
Profile 2 & 995 & $4.1778 * 10^{6}$ \\
Profile 3 & 995 & $4.156^{*} 10^{6}$ \\
\hline
\end{tabular}

\section{CONCLUSION}

From the calculations, Galvanized steel has been chosen as the material for the heat recovery shield as it leads to better results compared to ordinary steel. The thickness for the shield is chosen as $5 \mathrm{~mm}$ as it is more than enough and the number of shields to be installed is found to be 12 with gap of 0.545 meters between each shield as it leads to better heat storage in the slab compared to the other models. From the results of thermal transient Analysis, Profile I is selected as it is found to have the maximum heat storage within itself at the end of the process.

\section{FUTURE SCOPE}

For obtaining better results in the project heat flow analysis through the slab and shield can be performed through Computational Fluid Dynamics (CFD). But the greatest challenge in this analysis is the "Shape Factor Extraction".

\section{REFERENCE}

1. Yongqi Sun, Zuotai Zhang, Lili Liu and XidongWang.MultiStageControl of Waste Heat Recovery fromHigh Temperature Slags Based on Time Temperature Transformation Curves. Energies 2014, 7, 1673-1684; doi:10.3390/en7031673.

2. K. K. AnanthaKirthan, S. SathurthaMourian, M. Vignesh, A. Nisanth. Analysis of Temperature loss of Hot Metal during Hot Rolling Process at Steel Plant. IJMER ISSN: 2249-6645, Vol. 4 ,ISSN.8, Aug. 2014

3. Nisi, K., B. Nagaraj, and A. Agalya. "Tuning of a PID controller using evolutionary multi objective optimization methodologies and application to the pulp and paper industry." International Journal of Machine Learning and Cybernetics (2018): 1-11.

4. ShriP.K.Thakur, Shri K. Prakash, ShriK.G.Muralidharan, V.Bahl, Shris.Das. A review on: efficient energy optimization inReheating furnaces. International Journal of Mechanical and Production Engineering, ISSN: 2320-2092, Volume- 3, Issue-2, Feb.-2015.

5. L. E. Collins, F. Hamad, M. Kostic and T. Lawrence. Production of High Strength Line Pipe Steel by Steckel Mill Rolling and Spiral Pipe Forming. Frontier Pipe Research Unit, IPSCO.

6. "Heat and Mass Transfer by R.C. Sachdeva", Fourth Edition, New Age Publishers.
7. MujtabaAl.Mudhaffara, Nathera A. Saleh, AsmaaAassy. Influence of Hot Clad Rolling Process Parameters on life cycle of Reinforcedbar of Stainless Steel Carbon Steel Bars.Procedia Manufacturing 8 ( 2017 ) $353-360$ 